\title{
DESCRIÇÃO, PRODUTIVIDADE E ESTABILIDADE DA CULTIVAR DE SOJA IAC-23, RESISTENTE A INSETOS ${ }^{(1)}$
}

\author{
MANOEL ALBINO COELHO DE MIRANDA ${ }^{(2)}$; NELSON RAIMUNDO BRAGA ${ }^{(2)}$; \\ ANDRÉ LUIZ LOURENÇÃO ${ }^{(2,4)}$; FERNANDO TOLEDO SANTOS DE MIRANDA ${ }^{(3)}$; \\ SANDRA HELENA UNÊDA ${ }^{(3)}$; MARGARIDA FUMIKO ITO ${ }^{(2)}$
}

\begin{abstract}
RESUMO
A cultivar de soja IAC-23 foi obtida pelo método genealógico modificado, a partir do cruzamento BR-6 X IAC 83-23, tendo sido avaliada com a designação IAC 93-345, em 14 ambientes, nos Estados de São Paulo e de Minas Gerais. Os ensaios finais foram desenvolvidos em Conceição das Alagoas (MG), Mococa (SP) e Campinas (SP), em 1994/95; em Conceição das Alagoas, Campinas, Morro Agudo (SP) e Tarumã (SP) em 1995/96; Conceição das Alagoas, Mococa, Campinas, Morro Agudo, Tarumã e Ribeirão Preto (SP), em 1996/97; e em Campinas em 1998/99. Utilizou-se o delineamento de blocos ao acaso, com quatro repetições. Em semeaduras de novembro, esse cultivar precoce, com período juvenil longo, floresceu aos 43 dias, após a semeadura, e suas plantas atingiram $67 \mathrm{~cm}$ de estatura. A duração entre a emergência das plântulas e o estádio de maturação (R-8) foi de 106 dias, dentro do grupo de maturação precoce. O rendimento médio de grãos foi de $3.017 \mathrm{~kg} \cdot \mathrm{ha}^{-1}$. As plantas na maturação apresentam pubescência marrom e sementes amarelas com hilo marrom. Essa cultivar apresenta resistência às doenças pústula-bacteriana (Xanthomonas campestris pv. glycines), fogo-selvagem (Pseudomonas syringae pv. tabaci), cancro-da-haste (Diaporthe phaseolorum f. sp. meridionalis) e mancha-café ("soybean mosaic virus", SMV). Apresenta também resistência a insetos mastigadores e sugadores, semelhante à cultivar IAC-17 e superior à IAS-5. A produtividade e estabilidade apresentadas pela cultivar IAC-23 sugerem sua indicação para condições edafoclimáticas similares às dos experimentos realizados.
\end{abstract}

Palavras-chave: Glycine max, resistência a insetos.

\section{ABSTRACT \\ DESCRIPTION, YIELD AND STABILITY OF EARLY SOYBEAN INSECT RESISTANT CULTIVAR IAC-23}

The breeding line IAC 93-345(IAC-23) was selected from the cross BR-6 XIAC 83-23 through single seed descent method (SSD) to increase insect resistance, and was evaluated at fourteen environments at São Paulo (SP) and Minas Gerais (MG) States: Conceição das Alagoas (MG), Mococa and Campinas (SP)

$\left({ }^{1}\right)$ Recebido para publicação em 16 de fevereiro 2001 e aceito em 13 de novembro de 2002.

$\left(^{2}\right)$ Instituto Agronômico (IAC), Caixa Postal 28, 13001-970, Campinas (SP).

$\left({ }^{3}\right)$ Doutorando da Escola Superior de Agricultura "Luiz de Queiroz", Caixa Postal 9, 13418-900 Piracicaba (SP).

$\left({ }^{4}\right)$ Com bolsa de produtividade de pesquisa do CNPq. 
(1994/95); in Conceição das Alagoas, Mococa, Campinas, Morro Agudo, Tarumã and Ribeirão Preto (1996/ 97); and Campinas (1998/99). Conclusive trials were conducted in randomized blocks with four replications. This cultivar shows long juvenile period, flowering time at 43 days, and complete life cicle around 106 days after seed germination, with plant height about $67 \mathrm{~cm}$. The average yield was $3017 \mathrm{~kg}$.ha ${ }^{-1}$. Plants show brown pubescence, yellow seeds with brown hilum. The new cultivar is resistant to: bacterial pustule (Xanthomonas campestris pv. glycines), wildfire (Pseudomonas syringae pv. tabaci), stem canker (Phomopsis phaseoli f.sp. meridionalis) and soybean mosaic birus (SMV). IAC-23 productivity, large stability and resistance levels to leaf and pod feeders insects is similar to that observed for IAC-17, and superior to that of IAS-5. The cultivar IAC-23 is then recommended for cultivation in the State of São Paulo and in similar environmental conditions.

Key words: Glycine max, insect resistance.

\section{INTRODUÇÃO}

A soja é a mais importante oleaginosa no mundo, cujos teores de óleo e proteína nos grãos podem ultrapassar $20 \%$ e $40 \%$ respectivamente (RoEssing e GuedEs, 1993). Na safra brasileira de 2001/02, a área estimada de semeadura foi de 15,6 milhões de hectares com produção superior a 41 milhões de toneladas de grãos (CONAB, 2002, citado por Ribeiro e BARROS, 2002).

A recente descoberta de substâncias de valor medicinal na composição dos grãos de soja ampliou o interesse pelo seu cultivo e utilização. Entre os principais benefícios para a saúde humana têm sido destacados: a) teores elevados de ácidos graxos insaturados, como preventivos de altos índices de colesterol indesejável no sangue; b) presença de lecitina, que favorece o sistema imunológico; c) isoflavonas, saponinas e inibidores de protease (principalmente genótipos resistentes a insetos) que apresentam efeitos anticancerígenos; d) fibras com prováveis efeitos fisiológicos no controle de diabetes; e) redução de riscos de osteoporose( KoGAN, 1986; Vello e Tsuitsumi, 2000).

O atual programa de melhoramento genético de soja do Instituto Agronômico inclui entre seus principais objetivos a obtenção de cultivares resistentes a insetos, utilizando como fontes de resistência, germoplasma descendente das introduções PI 171451, PI 227687, PI 229358, e PI 274454 (LOURENÇÃo et al., 1989). Esses genótipos exóticos necessitam de vários ciclos de seleção para obtenção de cultivares resistentes comercializáveis.

As cultivares IAC-17 (precoce), IAC-18 (semiprecoce) e IAC-19 (médio) ganharam interesse, quando utilizadas, simultaneamente, em uma mesma propriedade, pelas suas características, que permitem maior eficiência no controle integrado de insetos e na racionalização do uso do solo e dos equipamentos. A utilização combinada desses cultivares reduz a probabilidade de efeitos climáticos desfavoráveis em fases críticas de formação de grãos nas plantas e durante a colheita.
A definição de nova cultivar exige que seja produtiva e também estável. Segundo BECKER (1981), não há concordância entre os melhoristas quanto à definição de estabilidade produtiva, embora não haja divergência quanto à sua importância para o melhoramento genético. Esse autor conceituou "estabilidade" de duas formas: 1) conceito biológico, em que o genótipo mostra uma produção constante em qualquer ambiente, apresentando variância mínima entre ambientes, equivalente ao conceito de "homeostase"; 2) conceito agronômico, em que o genótipo, considerado estável, mostra, em quaisquer condições ambientais, um comportamento previsível, não mostrando interação com ambiente.

O mesmo autor considera a ecovalência como uma medida adequada para quantificar a estabilidade no sentido agronômico. A ecovalência (Wi), definida por WRICKE e WEBER (1986) quantifica a contribuição de cada genótipo para o efeito da interação genótipo $\mathrm{X}$ ambiente, como também permite conhecer a significância dos desvios em relação à regressão linear $(b$, coeficiente angular $=1$, genótipo responsivo).

O objetivo deste trabalho foi mostrar o comportamento da cultivar IAC-23, resistente a insetos, em relação à produtividade e sua estabilidade, comparativamente às demais linhagens precoces testadas nos experimentos finais, além da descrição de suas características nos ambientes avaliados.

\section{MATERIAL E MÉTODOS}

No Centro Experimental de Campinas, do Instituto Agronômico, foi obtida variabilidade, a partir de cruzamentos manuais biparentais, de modo a obter progênies que combinassem os méritos dos pais. A genealogia das cultivares e linhagens componentes dos ensaios finais do grupo de maturação precoce para o Estado de São Paulo indica que havia fonte de juvenilidade longa e de resistência ao "cancro da haste", entre outras características, em todos os cruzamentos efetuados (Quadro 1 ). 
A cultivar IAC-23 é resultante do cruzamento entre BR-6 (Bragg resistente à doença olho-de-rã) e IAC 83-23, linhagem irmã de IAC-17. Ambos os progenitores apresentam boa resistência ao nematóide Meloidogyne javanica. 'IAC-23' corresponde ao terceiro retrocruzamento, a partir de PI 229358, em "background" de Bragg com juvenilidade longa proveniente de IAC-8. Foram efetuadas avaliações visuais de plantas e progênies nas gerações $\mathrm{F}_{4}$ e $\mathrm{F}_{5}$; as melhores linhagens selecionadas de ciclo precoce foram incluídas nos ensaios preliminares, conduzidos em lattice simples $6 \times 6$, nas localidades de Campinas, Conceição das Alagoas, Tarumã e Ribeirão Preto.

Para maior controle local, os sub-blocos foram dispostos no mesmo sentido das operações de manejo do solo. Nesses experimentos, as parcelas foram constituídas de três linhas de $4 \mathrm{~m}$ de comprimento, sendo a área útil para colheita representada por uma linha central de $3 \mathrm{~m}$, após a eliminação de $0,5 \mathrm{~m}$ de cada extremidade.

Nos experimentos finais de avaliação das melhores linhagens, o delineamento foi o de blocos ao acaso, com quatro repetições e parcelas de quatro linhas de semeadura, espaçadas em $0,5 \mathrm{~m}$, e com $5 \mathrm{~m}$ de comprimento.

O rendimento de grãos, expresso em kg.ha ${ }^{-1}$, foi estimado em área útil de $4,0 \mathrm{~m}^{2}$, utilizando-se as duas linhas centrais, excluindo-se as extremidades de $0,5 \mathrm{~m}$. A quantificação do efeito da interação genótipo $X$ ambiente foi efetuada através de análise conjunta dos 14 experimentos finais, inclusive dentro de cada local, com mais de um ano de experimentação.

As médias foram comparadas com o padrão IAS-5, pelo teste DunNeT a 5\%. A estabilidade dos genótipos foi medida pela ecovalência, de acordo com WRICKLE e WEBER (1986). Calculou-se a significância dos desvios em relação à regressão de acordo com Kang e Miller (1984), citado por Miranda (1999). As primeiras avaliações de resistência a insetos foram realizadas na fase de obtenção das linhagens $\left(\mathrm{F}_{6}\right)$, quando se atribuíram notas aos níveis de desfolhamento e de retenção foliar nas progênies. Outros ensaios foram posteriormente realizados por LOURENÇÃo et al. (2000).

Quadro 1. Análise da variância conjunta dos experimentos finais de soja desenvolvidos em cinco municípios do Estado de São Paulo e um de Minas Gerais, em 1994/95, 1995/96, 1996/97 e 1998/99

\begin{tabular}{|c|c|c|c|c|c|}
\hline Causas de variação & GL & SQ & QM & F & Prob $>F$ \\
\hline Local(L) & 13 & 131315043 & 10101157 & 33,84 & 0,00001 \\
\hline Genótipo(G) & 11 & 4306855 & 391532 & 1,31 & 0,22318 \\
\hline Interação(GxL) & 143 & 42689518 & 298528 & 2,07 & 0,00001 \\
\hline Blocos(B)/locais & 42 & 21412318 & 509817 & 3,54 & 0,01466 \\
\hline $\mathrm{B} / \mathrm{C}$ das Alagoas ${ }^{(1)}$ & 3 & 214518 & 71507 & 0,51 & 0,68958 \\
\hline $\mathrm{B} / \operatorname{Mococa}^{(1)}$ & 3 & 287643 & 85881 & 0,67 & 0,57749 \\
\hline B/Campinas ${ }^{(1)}$ & 3 & 201720 & 67240 & 0,47 & 0,71008 \\
\hline B/Campinas ${ }^{(2)}$ & 3 & 2579625 & 859874 & 5,97 & 0,00083 \\
\hline B/C. das Alagoas ${ }^{(2)}$ & 3 & 88542 & 29514 & 0,20 & 0,89322 \\
\hline B/M.Agudo (2) & 3 & 207604 & 69201 & 0,48 & 0,70063 \\
\hline $\mathrm{B} / \operatorname{Taruman}^{(2)}$ & 3 & 195175 & 65058 & 0,45 & 0,72063 \\
\hline B/Campinas ${ }^{(3)}$ & 3 & 14033387 & 4677796 & 32,45 & 0,00001 \\
\hline $\mathrm{B} / \operatorname{Tarumam}^{(3)}$ & 3 & 773853 & 257951 & 1,79 & 0,14674 \\
\hline $\mathrm{B} / \mathrm{Mococa}^{(3)}$ & 3 & 284633 & 94878 & 0,66 & 0,58188 \\
\hline B/C. das Alagoas ${ }^{(3)}$ & 3 & 669830 & 223277 & 1,55 & 0,19960 \\
\hline B/Morro Agudo ${ }^{(3)}$ & 3 & 38903 & 12968 & 0,09 & 0,96468 \\
\hline B/Ribeirão Preto ${ }^{(3)}$ & 3 & 521444 & 173815 & 1,21 & 0,30657 \\
\hline B/Campinas ${ }^{(4)}$ & 3 & 1315438 & 438479 & 3,04 & 0,02810 \\
\hline Resíduo & 462 & 66596688 & 144149 & & \\
\hline Total & 671 & 266320422 & & & \\
\hline
\end{tabular}

$\left({ }^{1}\right) 1994 / 95 .\left({ }^{2}\right) 1995 / 96 .\left(^{3}\right) 1996 / 97 .\left({ }^{4}\right) 1998 / 99$. 
Na produção de sementes genéticas, as plantas da cultivar IAC-23 foram submetidas a inoculação com isolados de Diaporthe phaseolorum f. sp. meridionalis cancro-da-haste, pelo método do "palito de dente", descrito por YorINORI (1994), para confirmar resistência ao patógeno, já verificada em campo.

$\mathrm{O}$ isolado patogênico deste fungo foi repicado em placas de Petri, contendo meio de cultura BDA (batata, dextrose, agar) e incubado à temperatura de $27^{\circ} \mathrm{C}$ a $28^{\circ} \mathrm{C}$. Cinco dias após a incubação, quatro discos de micélio, de $5 \mathrm{~mm}$ de diâmetro foram transferidos para as placas de Petri e cerca de 150 pontas de palitos de dente, cortadas a $1 / 4$ do palito, foram dispostas perpendicularmente num disco de papel de filtro na medida do diâmetro da placa de Petri, com a ponta afinada $5 \mathrm{~mm}$ acima do meio de cultura. Deste modo, as placas foram incubadas de 27 a $28^{\circ} \mathrm{C}$, durante cinco a sete dias.

As plantas de soja no estádio V-4 (FeHr e CAVINEsS, 1977) foram infectadas pela introdução da ponta do palito colonizado pelo fungo, na altura do segundo entrenó, e mantidas em casa de vegetação até a avaliação no estádio R-6 (FeHr e CAviness, 1977). As plantas com sintomas típicos foram consideradas suscetíveis, enquanto as que não apresentaram sintomas, resistentes.

\section{RESULTADOS E DISCUSSÃO}

A análise conjunta dos 14 experimentos finais revela que houve significância para os efeitos de locais e para a interação genótipo $\mathrm{x}$ ambiente (Quadro 1). O mesmo não ocorreu para o efeito de genótipo, dada a magnitude da interação observada. Uma provável causa foi a ocorrência de cancro-da-hast em algumas localidades, a exemplo de Campinas.

Os descritores morfológicos e fisiológicos da IAC-23 encontram-se no Quadro 2.

Quanto à produtividade vale registrar que as linhagens IAC 93-725, IAC 93-386 e IAC93-571 mostraram desempenhos equivalentes à da cultivar IAC-23 (Quadro 3). No entanto, a primeira mostrou-se suscetível ao cancro-da-haste em testes realizados em casa de vegetação, e a segunda linhagem foi menos estável, à semelhança da linhagem IAC 93-571, apresentando desvios significativos em relação à regressão linear, respondendo por $17,98 \%$ e $16,51 \%$, do quadrado médio da interação respectivamente (Quadro 4).

A estatura média das plantas da cultivar IAC23 foi de $67 \mathrm{~cm}$, valor intermediário entre o obtido pela IAC-17 e o do IAS-5.
Quadro 2. Descritores morfológicos e fisiológicos do cultivar de soja IAC-23

\section{MORFOLÓGICOS}

1. Cor do hipocótilo:

verde

2. Cor da pubescência:

marrom

3. Cor da flor:

4. Cor da vagem (sem pubescência):

branca

5. Cor da vagem (com pubescência):

marrom-clara

6. Cor do tegumento da semente:

7. Cor do hilo da semente:

marrom

amarela

marrom

\section{FISIOLÓGICOS}

8. Duração entre a emergência

e o florescimento:

9. Duração entre a emergência

e a a maturação:

10. Estatura das plantas na maturação: $67 \mathrm{~cm}$

11. Massa de 100 sementes:

43 dias

106 dias

$18 \mathrm{~g}$

12. Reação à pústula-bacteriana

(Xanthomonas campestris pv. glycines): resistente

13. Reação ao fogo-selvagem

(Pseudomonas seringae pv. tabaci): resistente

14. Reação ao cancro-da-haste

(Diaporthe phaseolorum f.sp. meridionalis): resistente

15. Reação ao mosaico-comum (VMCS): resistente

16. Reação aos nematóides

de galha(Meloidogyne sp):

resistente

17. Teor de óleo $(\%)^{(1)}$ :

19,6

18. Teor de proteína(\%) ${ }^{(2)}$.

38,9

$\left({ }^{1}\right)$ Extrator tipo Butt. $\left({ }^{2}\right)$ Método Kjeldahl

A duração do ciclo foi ligeiramente superior à de IAS-5 e semelhante à de IAC-17 (Quadro 3).

Verificou-se pela análise conjunta dentro de locais (Quadro 5) que houve significância para o efeito do ano em todos os locais, efeito de genótipo em Campinas e Conceição das Alagoas, e da interação G $x$ E em Conceição das Alagoas, e Mococa, sugerindo a viabilidade de regionalização da recomendação de cultivares por este critério.

A produtividade alcançada pela cultivar IAC23 foi $24 \%$ superior ao rendimento de IAS-5. Esta diferença foi significativa pelo teste DUNNET a 5\% em Conceição das Alagoas, onde o rendimento médio das linhagens testadas e da cultivar IAC-23 foram superiores aos valores das demais localidades, e a cultivar IAC-23 não diferiu significativamente dos cultivares-padrão (Quadro 6). 
Quadro 3. Genealogia, rendimento de grãos, índice relativo (IR) ao padrão IAS-5, estatura das plantas,duração dos períodos emergência-florescimento (EF) e emergência maturação (EM), em14 ensaios de soja conduzidos em Campinas, Mococa, Tarumã, Morro Agudo, Ribeirão Preto e Conceição das Alagoas, nos anos 1994/95, 1995/96, $1996 / 97$ e $1998 / 99$

\begin{tabular}{|c|c|c|c|c|c|c|}
\hline Genótipo & Genealogia & Rendimento de grãos & IR & Estatura das plantas & $\mathrm{EF}$ & EM \\
\hline & & kg.ha ${ }^{-1}$ & & $\mathrm{~cm}$ & 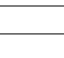 & $\bar{u}$ \\
\hline IAC93-725 & IAC-13 x IAC83-1003 & 3.059 & $(110)$ & 69 & 40 & 103 \\
\hline IAC93-386 & BR-6 x IAC83-23 & 3.020 & $(109)$ & 73 & 43 & 106 \\
\hline IAC-23 & BR-6 x IAC83-23 & 3.017 & $(109)$ & 67 & 43 & 106 \\
\hline IAC93-571 & IAS-5 x IAC-12 & 3.006 & $(108)$ & 68 & 44 & 107 \\
\hline IAC93-715 & IAC-13 x IAC83-1003 & 2.998 & $(108)$ & 74 & 43 & 106 \\
\hline IAC93-587 & IAS-5 x IAC-13 & 2.992 & $(108)$ & 74 & 43 & 106 \\
\hline IAC93-680 & IAC-13 x IAC83-1003 & 2.974 & $(107)$ & 76 & 42 & 104 \\
\hline IAC 93-582 & IAS-5 x IAC-12 & 2.969 & $(107)$ & 62 & 41 & 105 \\
\hline IAC-17 & D72-9601-1 x IAC-8 & 2.953 & $(106)$ & 74 & 45 & 106 \\
\hline IAC $93-598$ & IAS-5 x IAC-12 & 2.952 & $(106)$ & 68 & 41 & 104 \\
\hline IAC93-727 & IAC-13 x IAC $83-1003$ & 2.816 & $(102)$ & 69 & 39 & 103 \\
\hline IAS-5 & Hill x (Roanoke $\times$ Ogden $)$ & 2.774 & $(100)$ & 63 & 38 & 103 \\
\hline Média & & 2.961 & & 70 & 42 & 105 \\
\hline C.V.(\%) & & 12,8 & & & & \\
\hline
\end{tabular}

Quadro 4. Avaliação e seleção de genótipos de soja, tendo como atributos o rendimento de grãos $\left(\mathrm{kg} \cdot \mathrm{ha}^{-1}\right)$ e a ecovalência expressa em porcentagem da soma de quadrados da interação genótipo X ambiente (W\%) e significância em relação aos desvios da regressão

\begin{tabular}{|c|c|c|c|c|c|}
\hline \multirow[b]{2}{*}{ Genótipo } & \multirow[b]{2}{*}{ Rendimento de grãos } & Méritos & \multicolumn{2}{|c|}{ Critérios $(*)$} & \multirow[b]{2}{*}{ Seleção $\left.{ }^{* *}\right)$} \\
\hline & & Ecovalência & $>$ IAS-5 & $\begin{array}{c}\text { Significância } \\
\text { dos desvios }\end{array}$ & \\
\hline & kg.ha ${ }^{-1}$ & $\mathrm{~W} \%$ & & & \\
\hline IAC93-725 & 3.059 & 3,78 & 1 & 1 & $S$ \\
\hline IAC93-386 & 3.020 & 17,98 & 1 & 0 & $\mathrm{~N}$ \\
\hline IAC-23 & 3.017 & 7,14 & 1 & 1 & $\mathrm{~S}$ \\
\hline IAC93-571 & 3.006 & 16,51 & 1 & 0 & $\mathrm{~N}$ \\
\hline IAC93-715 & 2.998 & 2,55 & 1 & 1 & $S$ \\
\hline IAC 93-587 & 2.992 & 1,94 & 1 & 1 & $S$ \\
\hline IAC93-680 & 2.974 & 6,49 & 1 & 1 & $S$ \\
\hline IAC 93-582 & 2.969 & 8,5 & 1 & 1 & $\mathrm{~S}$ \\
\hline IAC-17 & 2.953 & 13,28 & 1 & 0 & $\mathrm{~N}$ \\
\hline IAC 93-598 & 2.952 & 8,84 & 1 & 0 & $\mathrm{~N}$ \\
\hline IAC 93-727 & 2.816 & 4,98 & 1 & 1 & $S$ \\
\hline IAS-5 & 2.774 & 8,01 & 0 & 0 & $\mathrm{~N}$ \\
\hline Média & 2961 & & & & \\
\hline Soma & 100,00 & & & & \\
\hline
\end{tabular}

$(*) \quad 1=$ rendimento superior ao do cultivar IAS-5 e com desvios não significativos; $0=$ rendimento inferior ao do cultivar IAS-5 e com desvios significativos; $(* *)$ S=Selecionado; N= Refugado. 
Quadro 5. Análise da variância dentro de locais, Campinas (94/95, 95/96, 96/97 e 98/99), Conceição das Alagoas (94/ 95, 95/96 e 96/97), Morro Agudo (95/96,e 96/97), Tarumã ( 95/96 e 96/97), Mococa ( $94 / 95$ e 96/97)

\begin{tabular}{|c|c|c|c|c|c|}
\hline & $\begin{array}{l}\text { Graus de } \\
\text { Liberdade }\end{array}$ & $\begin{array}{c}\text { Soma de } \\
\text { Quadrados }\end{array}$ & $\begin{array}{l}\text { Quadrado } \\
\text { Médio }\end{array}$ & Valor F & Prob. $>$ F \\
\hline \multicolumn{6}{|l|}{ Campinas } \\
\hline Ano & 3 & 26768362,43 & 8922787,48 & 37,68 & 0,00001 \\
\hline Genótipo & 11 & 7565129,02 & 687739,00 & 2,9 & 0,00883 \\
\hline Interação GXA & 33 & 7814897,26 & $236815,071,02$ & 0,44831 & \\
\hline Bloco / Ano & 12 & 18130171,10 & 1510847,59 & 6,51 & 0,00063 \\
\hline Resíduo & 132 & 30616796,16 & 231945,43 & & \\
\hline Total & 191 & 23657644,06 & & & \\
\hline \multicolumn{6}{|c|}{ Conceição das Alagoas } \\
\hline Ano & 2 & 9700855,12 & 4850427,56 & 27,59 & 0,00001 \\
\hline Genótipo & 11 & 7757423,35 & 705221,12 & 4,01 & 0,00299 \\
\hline Ínteração GXA & 22 & 3867739,71 & 175806,35 & 2,08 & 0,00772 \\
\hline Bloco/Ano & 9 & 972889,73 & 108098,86 & 1,28 & \\
\hline Resíduo & 99 & 8350037,02 & 84343,81 & & \\
\hline Total & 143 & 30648953,94 & & & \\
\hline \multicolumn{6}{|l|}{ Morro Agudo } \\
\hline Ano & 1 & 6889745,04 & 6889745,04 & 35,55 & 0,00022 \\
\hline Genótipo & 11 & 4757602,71 & 432509,34 & 2,23 & 0,09947 \\
\hline Interação GXA & 11 & 2131790,21 & 193799,11 & 1,12 & 0,35773 \\
\hline Bloco / Ano & 6 & 246507,58 & 41084,60 & 0,23 & 0,87008 \\
\hline Resíduo & 66 & 11386708,42 & 172525,89 & & \\
\hline Total & 95 & 25412353,96 & & & \\
\hline \multicolumn{6}{|l|}{ Tarumã } \\
\hline Ano & 1 & 5529599,99 & 5529599,99 & 31,09 & 0,00033 \\
\hline Genótipo & 11 & 4154276,96 & 377661,54 & 2,12 & 0,11372 \\
\hline $\begin{array}{l}\text { Interação GXA } \\
0,19793\end{array}$ & & 11 & 1956170,50 & 177833,68 & 1,39 \\
\hline Bloco / Ano & 6 & 969028,96 & 161504,83 & 1,26 & 0,29633 \\
\hline Resíduo & 66 & 8438942,54 & 127862,77 & & \\
\hline Total & 95 & 21048018,96 & & & \\
\hline \multicolumn{6}{|l|}{ Mococa } \\
\hline Ano & 1 & 23935044,01 & 23935044,01 & 77,29 & 0,00003 \\
\hline Genótipo & 11 & 2276477,86 & 206952,53 & 0,67 & 0,74305 \\
\hline $\begin{array}{l}\text { Interação GXA } \\
0,00251\end{array}$ & & 11 & 3406352,86 & 309668,44 & 3,07 \\
\hline Bloco / Ano & 6 & 572276,56 & 95379,43 & 0,95 & 0,57447 \\
\hline Resíduo & 66 & 6656754,69 & 100859,92 & & \\
\hline Total & 95 & 36846905,99 & & & \\
\hline
\end{tabular}


Quadro 6. Rendimento de grãos e índice relativo ao padrão IAS-5 de 12 genótipos de soja em experimentos desenvolvidos no período $1994 / 98$

\begin{tabular}{|c|c|c|c|c|c|c|c|c|c|c|c|c|c|c|}
\hline \multirow[t]{2}{*}{ Genótipo } & \multicolumn{2}{|c|}{ Campinas $^{(1)}$} & \multicolumn{2}{|c|}{ C. Alagoas ${ }^{(6)}$} & \multicolumn{2}{|c|}{ Mococa $^{(2)}$} & \multicolumn{2}{|c|}{ Tarumã $\tilde{a}^{(3)}$} & \multicolumn{2}{|c|}{ M. Agudo ${ }^{(4)}$} & \multicolumn{2}{|c|}{ Ribeirão Preto ${ }^{(5}$ ) } & \multicolumn{2}{|r|}{ Média } \\
\hline & $\mathrm{kg} \cdot \mathrm{ha}^{-1}$ & & $\mathrm{~kg} \cdot \mathrm{ha}^{-}$ & & $\mathrm{kg} \cdot \mathrm{ha}^{-1}$ & & $\mathrm{~kg} \cdot \mathrm{ha}^{-1}$ & & kg.ha-1 & & $\mathrm{kg} \cdot \mathrm{ha}^{-1}$ & & $\mathrm{~kg} \cdot \mathrm{ha}$ & \\
\hline IAC93-725 & 2.454 & $(113)$ & 3.323 & $(111)$ & 3.126 & $(115)$ & 3.408 & $(100)$ & 2.819 & $(123)$ & 3.138 & $(96)$ & 3.095 & $(108)$ \\
\hline IAC93-386 & 2.407 & (99) & 3.719 & (124) & 3.007 & $(110)$ & 3.229 & $(95)$ & 2.937 & $(128)$ & 3.150 & $(96)$ & 3.075 & $(108)$ \\
\hline IAC93-582 & 2.590 & (107) & 3.274 & $(110)$ & 3.140 & $(115)$ & 3.507 & (103) & 2.330 & $(101)$ & 3.431 & $(105)$ & 3.045 & (107) \\
\hline IAC93-715 & 2.716 & $(112)$ & 3.302 & $(110)$ & 3.057 & (112) & 3.379 & (99) & 2.530 & $(110)$ & 3.272 & $(100)$ & 3.043 & (107) \\
\hline IAC-23 & 2.743 & $(113)$ & 3.708 & $(124)$ & 2.856 & $(105)$ & 3.217 & $(94)$ & 2.400 & $(104)$ & 3.197 & $(98)$ & 3.020 & (106) \\
\hline IAC93-571 & 3.111 & $(128)$ & 3.334 & (111) & 2.895 & (106) & 2.676 & (79) & 2.490 & (108) & 3.522 & (107) & 3.005 & (105) \\
\hline IAC93-587 & 2.795 & (115) & 3.312 & $(111)$ & 2.898 & (106) & 3.237 & (95) & 2.730 & (119) & 3.047 & (93) & 3.003 & (105) \\
\hline IAC93-680 & 2.884 & (119) & 3.146 & (105) & 3.220 & (118) & 3.178 & (93) & 2.377 & (103) & 3.119 & $(95)$ & 2.986 & (105) \\
\hline IAC-17 & 2.503 & (103) & 3.625 & (121) & 2.868 & $(105)$ & 3.032 & (89) & 2.810 & (122) & 3.041 & (93) & 2.980 & (104) \\
\hline IAC93-598 & 2.910 & $(120)$ & 3.052 & (102) & 2.997 & (110) & 3.319 & (97) & 2.491 & (108) & 2.916 & (89) & 2.948 & (103) \\
\hline IAS-5 & 2.430 & $(100)$ & 2.990 & $(100)$ & 2.728 & $(100)$ & 3.408 & $(100)$ & 2.298 & $(100)$ & 3.278 & (100) & 2.855 & $(100)$ \\
\hline IAC93-727 & 2.646 & (109) & 3.146 & (105) & 2.709 & (99) & 3.239 & $(95)$ & 2.228 & (97) & 3.056 & (93) & 2.837 & (99) \\
\hline Média & 2.707 & & 3.328 & & 2.958 & & 3.235 & & 2.537 & & 3.180 & & 2.991 & \\
\hline $\mathrm{CV} \%$ & 17,1 & & 8,7 & & 10,8 & & 11,0 & & 16,4 & & 5,9 & & & \\
\hline DMS 5\% & 416 & & 292 & & n.s. & & n.s. & & n.s. & & 334 & & & \\
\hline
\end{tabular}

$\left({ }^{1}\right) 1994 / 95,1995 / 96,1996 / 97$ e 1998/99. $\left({ }^{2}\right) 1994 / 95$ e 1996/97. $\left(^{3}\right) 1995 / 96$ e 1996/97. $\left({ }^{4}\right)$ 1995/96 e 1996/97. $\left({ }^{5}\right) 1996 / 97 .\left({ }^{6}\right) 1994 / 95,1995 / 96$ e $1996 / 97$. 
Na seleção das linhagens seguiram-se as recomendações de Miranda (1999), em que os seguintes critérios foram considerados: a) produtividade superior ao padrão IAS-5; ecovalência expressa em porcentagem da soma dos quadrados da interação; c) significância dos desvios da regressão. Nesse caso, seis linhagens foram passíveis de seleção: IAC 93-725, IAC-23, IAC 93-715, IAC 93-587, IAC 93-680 e IAC 93-727. Vale destacar que todas as linhagens descendentes de IAC 13 X IAC 83-1003, ou seja, IAC 93-725, IAC 93715, IAC 93-680 e IAC 93-727 comportaram-se como estáveis, comparativamente aos padrões IAC-17 e IAS5 , pelo conceito agronômico.

Em face de seus baixos valores de ecovalência, isto é, da porcentagem correspondente à variância da interação cultivar $X$ ambiente, e pela não-significância dos seus desvios em relação à regressão, em decorrência do período juvenil bem definido, essas linhagens apresentam genes para esse requisito nos respectivos parentais. No entanto, na avaliação para conferir resistência ao cancro-da-haste esse genótipo se mostrou suscetível. Desse modo, a linhagem IAC 93-725 que se destacou quanto à produtividade e estabilidade não foi indicada para cultivo devido à suscetibilidade a este fitopatógeno pelo teste do palito-de-dente em casa de vegetação.

Em relação à resistência aos insetos, a cultivar IAC-23, que se havia destacado em avaliações preliminares, na fase de obtenção de linhas puras, com menor incidência de danos a insetos, foi avaliada especificamente para insetos mastigadores e sugadores (LOURENÇÃO, 2000). Esses autores comprovaram que a cultivar IAC-23 sofreu danos, na ordem de $15,8 \%$, em sua área foliar por ataque da Anticarsia gemmatalis semelhante aos danos sofridos pela cultivar IAC-17 $(11,7 \%)$, mas diferindo significativamente de IAS-5 que teve $27,5 \%$ de sua área foliar ingerida pela lagarta.

Quanto a percevejos, os mesmos autores apontaram que a cultivar IAC-23 apresentou $25,4 \%$ de incidência de retenção foliar, superior a 7,1\% de IAC-17, padrão resistente, mas significativamente inferior ao índice de retenção ocorrido no padrão suscetível IAS-5, que foi de $76 \%$. Por outro lado, o índice de danos nas vagens da cultivar IAC-23 foi de $17,0 \%$, enquanto em IAC- 17 esse índice foi de $17,9 \%$ e em IAS-5 foi de $27,8 \%$.

Quanto à produtividade, na presença de percevejos, se considerados os grãos sadios e os não-deformados, o desempenho da nova cultivar foi superior aos padrões: 505,8 g/3 metros lineares, ou $3.372 \mathrm{~kg} \cdot \mathrm{ha}^{-1}$, superior aos padrões IAC-17 com 459,7 g/3 m, ou 3.065 kg.ha ${ }^{-1}$, e IAS--5 com 339,3 g/3 m, ou 2.262 kg.ha $^{-1}$.
Nesse caso, deve ser assinalado que as cultivares resistentes a insetos ganham maior importância onde se pretende minimizar a agressão ao meio ambiente, e se ainda contam com maiores teores de substâncias medicinais presentes nesses genótipos.

\section{CONCLUSÃO}

1. A cultivar IAC-23, pelas suas características morfo-fisiológicas e seu desempenho agronômico, pode ser indicada para cultivo nas condições edafoclimáticas do Estado de São Paulo e regiões limítrofes similares.

\section{REFERÊNCIAS BIBLIOGRÁFICAS}

BECKER, H.C. Correlations among some statistical measures of phenotypic stability. Euphytica, Dordrecht, v.30, p.835-840, 1981.

FEHR, W.R.; CAVINESS, C.E. Stages of soybean development. Ames: Iowa State University of Science and Technology, 1977.11p. (Special Report 80).

KANG, M.S.; MILLER, J.D. Genotypes X environment interaction for cane and sugar yield and their implications in sugarcane breeding. Crop Science, Madison, v. 24, p.435-440, 1984.

KOGAN, M. Plant defense strategies and host-plant resistance. In: KOGAN, M.(Ed.) Ecological theory and integrated pest management practice. New York: JohnWiley and Sons, 1986. p.83-134.

LOURENÇÃO, A.L.; COSTA, A S.; MIRANDA, M.A C. de. Sources of resistance to Insect pests and virus vector in the soybean gemplasm tested at Instituto Agronomico, SP, Brasil. In: WORLD SOYBEAN RESEARCH CONFERENCE, 4., 1989, Buenos Aires. Anais... Buenos Aires: Editora S.R.L., 1989. p.1578-1581.

LOURENÇÃO, A L.; PEREIRA, J.C.V.N.A ; MIRANDA, M.A C.; AMBROSANO, G.M.B. Avaliação de danos causados por percevejos e por lagartas em genótipos de Soja de ciclos precoce e semiprecoce. Pesquisa Agropecuária Brasileira, Brasília, v.35, p.879-886, 2000.

MIRANDA, F.T.S. Interação genótipos $x$ ambientes em linhagens de sojaselecionadas para resistência ao nematóide de cisto. 1999. 141p. Dissertação(Mestrado) , Escola Superior de Agricultura "Luiz de Queiroz", USP, Piracicaba.

RIBEIRO, J.F.; BARROS, J.S. O impacto da soja na biodiversidade do cerrado: desafios para a sustentabilidade. In: CONGRESSO BRASILEIRO DE SOJA, 2.,2002, Foz do Iguaçu. Anais .Foz de Iguaçu: Embrapa, 2002. p.24-35.

ROESSING, A C.; GUEDES, L.C.A. Aspectos econômicos do complexo soja: sua participação na economia brasileira e evolução na região do Brasil Central. In: ARANTES, N.E.; SOUZA, P.I.M. (Eds.) Cultura da soja nos cerrados. Piracicaba: Associação Brasileira da Potassa e do Fosfato, 1993, p. 1-70. 
VELLO, N. A ; TSUTSUMI, C.Y. A soja na prevenção e tratamento de doenças crônicas. In: CONGRESSO DE TECNOLOGIA E COMPETIVIDADE DA SOJA NO MERCADO GLOBAL, 2000, Cuiabá. Anais... Cuiabá: Fundação MT, 2000. p.135-140.

YORINORI, J.T. Método do palito-de-dente, uma seleção de genótipos de soja com resistência ao cancro-da-haste. In: REU-
NIÃO DE PESQUISA DE SOJA DA REGIÃO CENTRAL DO BRASIL, 16., 1994, Dourados. Ata e Resumos ... Londrina, Embrapa, 1994. p. 130-131.

WRICKE, G.; WEBER, E.W. Quantitative genetics and selection in plant breeding. Berlin/ New York: Walter de Gruyter, 1986, 406p. 